\title{
sciendo
}

\section{Presentation skills of business and economics students: Cluster analysis}

\author{
Tamara Ćurlin \\ University of Zagreb, Faculty of Economics and Business, Croatia \\ tcurlin@efzg.hr \\ Mirjana Pejić Bach \\ University of Zagreb, Faculty of Economics and Business, Croatia \\ mpejic@efzg.hr
}

Ivan Miloloža

University of J. J. Strossmayer in Osijek - Faculty for Dental Medicine \& Health ivan.miloloza@fdmz.hr

\begin{abstract}
Presentation skills are one of the most important tools that are required on numerous occasions in education and business. In most of the business and economics colleagues, presentation skills are taught as part of the curriculum, of at least several courses. Therefore, it could be expected that presentation skills would be highly developed among business and economics students. However, in practice, people develop numerous fears and barriers to the presentation in public. On the other hand, students do not behave in the same manner taking into account their fear towards the presentation in public. The goal of the paper is to investigate if there are homogenous groups of students according to their attitude towards the presentation, both as sources of success and as a source of fear. Cluster analysis has been employed to fulfil the paper goal. Non-hierarchical k-means analysis has been conducted on data collected by the research instrument about the benefits and fears from the presentations on the sample of students enrolled in business and economics colleagues. Results indicate that there are homogenous groups of students according to presentation perceived benefits and fears, but the composition of these groups indicates that perceived benefits and fears of presentations are not always related in the same direction.
\end{abstract}

Keywords: education, k-means, presentation anxiety, presentation skills.

JEL classification: A23, 123.

DOI: 10.2478/crebss-2020-0009

Received: November 8, 2020

Accepted: November 24, 2020

\section{Introduction}

Oral presentation skills are nowadays highlighted as one of the most important business communication tools (Coffelt, Baker, Corey, 2016). Numerous professions such as Economy and Business, Health, Politics, and Diplomacy recognised the 
influence of polished presentation skills as a necessity for a successful career (Ciarocco, 2018). They use presentations for business results discussions, developing strategies, pitching ideas, debating about their opinions, but the impact of the presented depends on the speakers' oral presentation skills (Salem, 2019). Academic researchers acknowledge presentation skills as the most important skills for employment, even in comparison to intelligence, moreover, they point out that poor presentation skills could impede the individual's career (Lent, 2018). Educators expect their graduates to have admirable communication skills so they can become more competitive future job applicants (Brynjolfsson, Rock, Syverson, 2017).

The relevance of presentation delivery cannot be emphasised enough for individuals' career whose success relies on their communication skills with their business associates, partners, and colleagues (Mohammed, 2019). However, not all managers perform well in delivering presentations. There are still several managers who neglect the importance of presentation skills, and there is a number of them who developed some kind of fear towards the presentation in public (Werthes, Maver, Brettel, 2018). There are various types and origins of fears and anxieties towards oral presentation deliveries, although numerous academics confirmed that the fear is lower when the material is well-rehearsed (Leigh, Claek, 2018). Therefore, for a person to develop full potential from their presentation skills, it is important to learn and evolve them from the earliest stages of education (Dede, 1996).

Oral presentation, debating and persuasion skills are included in curricula even in elementary schools nowadays (Roy, Macchiette, 2005). Learning presentation skills should not be limited to communication subjects, they should be nurtured at all times, and be included in different sorts of tasks so that students learn to organise information, connect to their audience, time and management, develop both inter and intrapersonal communication skills by balancing from serious to relaxed tone to keep their audience attentive and evolved (Roussel, Joulia, Tricot, 2017).

The purpose of this paper is to explore the business students' attitudes toward presentation delivery, and investigate if there are homogenous groups of students according to their attitude towards the presentation, both as sources of success and as a source of fear. If the investigation confirms that students could be sorted into groups, it could be helpful for future investigations on the topic, in the search for answers in finding the origin of fear as well as the possible solutions and the factors, which can reduce or eliminate the fear. The research is conducted by cross-analysis of descriptive statistics, factor analysis, cluster analysis, and the non-hierarchal kmeans analysis to extract the most knowledge as possible from the data presented.

The paper is organized in the following manner. After the Introduction, the Literature review is presented which provides deeper insight on the topic with relevant previous investigations included. Following, the Methodology section where methodology, data, sample characteristics, and the statistic analyse are described. The result section provides an interpretation of the statistical outputs from the research. The discussion section highlights the findings from the investigation. Finally, the Conclusion section provides the key knowledge from the research followed by the limitations and future investigation recommendations alongside the concluding remarks.

\section{Literature review}

Business schools pay special attention to teaching oral presentation skills to prepare their students for competitive and asperously business surroundings of the modern world (Ramesh, 2010). In business schools, excellent presentation skills are understood as the set of abilities that provide students to engage with the public during presentation delivery, clearly transmitting the knowledge, interacting, and understand 
the mindset of the audience (Cleverism, 2020). Moreover, higher education institutions emphasise presentation skills as they provide enhanced learning process and develop creativity and articulation (Henard, Roseveare 2012). Presentations make students open their minds and comprehended different concepts and methods, and remember the learned material for a longer period (Çetin, Eymur, 2017).

Suktikanaport (2014) investigated a sample of 280 department heads in various business fields, where respondents associated different communication skills to succeed. The oral communication skills, alongside writing skills, were rated higher than all other communication skills. The study concluded that refined presentation skills are essential not only to individuals' business success but to the whole company.

The fear of presentation delivery is another distinctive reason for institutions to include presentations into curricula. Many people experience occasional or permanent fear and anxiety of public speakers, and the educators' goal is to reduce it or eliminate it. Furthermore, the fear of presentation delivery soon became a prominent source for academic researches. Numerous authors investigate difficulties with presentation delivery and explored different ways to eliminate anxiety and improve the quality of the presentation performance (Dell'osso, Saettoni, Papasogli, 2002).

The preliminary papers on the topic were focused on the solutions for oral presentation anxiety. Rubin, Rubin, Jordan (1997) paper was the first who suggested that the practice and the repetition are the pivotal methods for stress elimination and performance improvement during presentation delivery. Alshare, Hindi (2004) recognised that oral presentations in the classroom are beneficial to both students and educators. The authors stressed out computer-based student presentations as a valuable teaching method for students to achieve a deeper understanding of the curricula. A year later, Susskind (2005) confirmed the previous research and connected the MS PowerPoint usage in the classroom with student confidence, motivation, self-efficiency, and success on the task. Some authors, such as Sukitkanaporn, Phoocharoensil (2013), and Christianson, Payne (2011) concentrated on attempts to determine elements of a successful presentation and the factors that increase presentation-delivering anxiety.

Sideris and Kafetsios (2008) introduced the connection between the parenting environment and the anxiety during presentation delivery. The same authors in 2008 presented another investigation result where they correlate parenting styles with the levels of fear while presentation delivery and school task performance (Sideridis, Kafetsios, 2008). A recent investigation from Sugeng and Suryani (2018) confirm the previous work findings and distinguishes self-confidence as the key factor of presentation delivery, and state that students' self-confidence depends on both parents and educators. Discoveries from such researches were highly useful for schools and other educational institutions, where they could implement acknowledged supportive communication methods which positively impacted students results, confidence, and, consequently, presentation skills (Šimičević, Jurić, Ćurlin, 2020).

Numerous methods concentrated on practical methods that enhance students' presentation delivery performance. Already mentioned authors, Christianson, Payne (2011) came up with a format that helps students with visual effects and time management which resulted in more convincing and engaging presentations. Popescu (2013) identified student attitudes toward public speech and tested their skills in presentation delivery. Authors Van Ginkel, Gulikers, Biemans, 2017), made a significant impact by carrying out an extensive literature review where they synthesized the data from all previous investigations on the topic and as a result produced the key seven principles for developing oral competences. 
In the year Çetin and Eymur (2017) introduce a novel conceptual model based on the argument-driven inquiry (ADI) developed on the social cognitive theories of learning which helped students to increase their presentation skills. Recent investigations on the topic also rely on disruptive technologies as a key factor which improves presentation delivery, Boetje, Van Ginkel (2020) emphasise virtual reality as a method to practice presentation skills where both anxious and non-anxious students gained benefits from practising before a VR audience, while McGovern, Moreira and Luna-Nevarez (2020) allowed the participants of the research to assess and upgrade their oral presentations skills. The investigation establishes that the usage of AR can be highly valuable to educational institutions to increase their oral presentation performance and reduce anxiety and fear by delivering it.

\section{Methodology Data}

This research has been conducted on a sample of 495 students Business and Economics students from Zagreb, Croatia. The final sample consist of a total of 367 female and 128 male students range from 18 to 25 years old. Most students were 21 $(39,8 \%)$ years old, following the age group of $22(18 \%)$, and $19(15.4 \%)$ years old. $10.9 \%$ of respondents were 23 years old, and $5.9 \%$ of respondents were 24 years old. 17 students (3.4\%) had 25 years while participating in this investigation, and, finally, only 1 student $(0.2 \%)$ was 18 years old. The majority of respondents fell into the age group between 19 and 23 years old.

Table 1 Sample characteristics

\begin{tabular}{|c|c|c|c|}
\hline & Frequency & $\%$ & Cumulative \% \\
\hline \multicolumn{4}{|c|}{ Gender } \\
\hline Male & 128 & 25.9 & 25.9 \\
\hline Female & 367 & 74.1 & 100 \\
\hline \multicolumn{4}{|c|}{ Age } \\
\hline 18 years & 1 & 0.2 & 0.2 \\
\hline 19 years & 76 & 15.4 & 15.6 \\
\hline 20 years & 32 & 6.5 & 22 \\
\hline 21 years & 197 & 39.8 & 61.8 \\
\hline 22 years & 89 & 18 & 79.8 \\
\hline 23 years & 54 & 10.9 & 90.7 \\
\hline 24 years & 29 & 5.9 & 96.6 \\
\hline 25 years & 17 & 3.4 & 100 \\
\hline \multicolumn{4}{|c|}{ Type of school } \\
\hline Gymnasium & 261 & 52.7 & 52.7 \\
\hline Business secondary school & 203 & 41 & 93.7 \\
\hline Another secondary school & 31 & 6.3 & 100 \\
\hline Total & 495 & 100 & \\
\hline
\end{tabular}

Source: Authors' work.

The respondents finished three different types of secondary schools in Croatia: gymnasium, business secondary school, and other secondary schools. More than half of students came from gymnasium (52.7\%), $41 \%$ graduated business secondary schools and $6.3 \%$ finished other secondary schools. Table 1 displays sample characteristics obtained for the research purpose. 


\section{Research instrument}

Given the research topic, the study is based on the questionnaire for measuring the perceived benefits and fears of delivering presentations. The research instrument was comprised out of four dimensions: (i) Fear at delivering presentation, (ii) Problems while delivering a presentation, (iii) Perceived success at delivering a presentation, and (iv) Strategies in stimulating audience attention when presenting.

Table 2 Research instrument measuring perceived benefits and fears of delivering presentations

\begin{tabular}{|c|c|c|}
\hline Dimension & Research items & Measurement \\
\hline $\begin{array}{l}\text { Fear at } \\
\text { delivering } \\
\text { presentations }\end{array}$ & $\begin{array}{l}\text { Q1_1. Fear that I will be unsuccessful / at } \\
\text { the presentation } \\
\text { Q1_2. Fear of being criticized } \\
\text { Q1_3. Fear that I will turn out funny } \\
\text { Q1_4. Fear that my colleagues will make } \\
\text { fun of me } \\
\text { Q1_5. Fear of revenge }\end{array}$ & $\begin{array}{l}\text { Likert scale (1-fear is not } \\
\text { present at all, 2-fear is } \\
\text { rarely present, 3-fear is } \\
\text { sometimes present, 4-fear } \\
\text { is often present, 5-fear is } \\
\text { always present) }\end{array}$ \\
\hline $\begin{array}{l}\text { Problems } \\
\text { while } \\
\text { delivering } \\
\text { the } \\
\text { presentation }\end{array}$ & $\begin{array}{l}\text { Q2_1. What about the hands? } \\
\text { Q2_2. How loud to speak? } \\
\text { Q2_3. What if the public reacts badly? } \\
\text { Q2_4. What if I have too much material? } \\
\text { Q2_5. What if I have too little material? } \\
\text { Q2_6. What if my voice starts to tremble? } \\
\text { Q2_7. What if I misjudge the time? }\end{array}$ & $\begin{array}{l}\text { Likert scale (1-problem is } \\
\text { not present at all; 2- } \\
\text { problem is rarely present; } \\
\text { 3-problem is sometimes } \\
\text { present; 4-problem is often } \\
\text { present; 5-problem is } \\
\text { always present) }\end{array}$ \\
\hline $\begin{array}{l}\text { Perceived } \\
\text { success at } \\
\text { delivering a } \\
\text { presentation }\end{array}$ & $\begin{array}{l}\text { Q3_1. I know well the material I expose } \\
\text { when I present } \\
\text { Q3_2. I look convincing when I present } \\
\text { Q3_3. I respect the audience and their } \\
\text { views when I present } \\
\text { Q3_4. I adapt the presentation to the } \\
\text { audience } \\
\text { Q3_5. I hold the audience's attention } \\
\text { throughout the presentation }\end{array}$ & $\begin{array}{l}\text { Likert scale (1-I do not } \\
\text { agree at all; 2-not agree; } \\
\text { 3-undecided; 4-agree; 5- } \\
\text { fully agree) }\end{array}$ \\
\hline $\begin{array}{l}\text { Strategies in } \\
\text { stimulating } \\
\text { audience } \\
\text { attention } \\
\text { when } \\
\text { presenting }\end{array}$ & $\begin{array}{l}\text { Q6_1. I surprise the audience with } \\
\text { something } \\
\text { Q6_2. I ask the audience a question } \\
\text { Q6_3. I pique the audience's curiosity } \\
\text { Q6_4. I remind the audience of something } \\
\text { that everyone remembers } \\
\text { Q6_5. I say something dramatic } \\
\text { Q6_6. I'm quoting something } \\
\text { Q6_7. I am briefly silent to highlight part of } \\
\text { the speech }\end{array}$ & $\begin{array}{l}\text { Likert scale (1-I do not } \\
\text { agree at all; 2-not agree; } \\
\text { 3-undecided; 4-agree; 5- } \\
\text { fully agree) }\end{array}$ \\
\hline
\end{tabular}

Source: Authors' work.

The fear of delivering presentations dimension rates of fear of presentations between students measured by Likert scale as (1-fear is not present at all, 2-fear is rarely present, 3-fear is sometimes present, 4-fear is often present, 5-fear is always present). Research items for Fear at delivering presentation dimensions are connected to fear of unsuccessful presentation, fear of criticism, fear of being mocked at, and fear of revenge.

The second dimension, Problems while delivering a presentation, examines problems that may occur while delivering the presentation, and consists of seven research item questions: (i) What about the hands? (ii) How loud to speak? (iii) What if 
the public reacts badly? (iv) What if I have too much material? (v) What if I have too little material? (vi) What if my voice starts to tremble? (vii) What if I misjudge the time? Research items are measured with a Likert scale as (1-problem is not present at all; 2problem is rarely present; 3-problem is sometimes present; 4-problem is often present; 5 -problem is always present).

The third dimension, Perceived success at delivering a presentation is focused on affirmative questions regarded to presentation performance and knowledge of the material, convincing performance, and connection with the audience. Dimension is also measured by the Likert scale as (1-I do not agree at all; 2-not agree; 3-undecided; 4-agree; 5-fully agree).

The fourth and final dimension contained in this investigation is Strategies in stimulating audience attention when presenting which include seven questions related to strategies of stimulating audience while presenting such as including quotes, questions, pauses, and surprises into the presentation. The simulating strategies dimension is measured by the Likert scale as the Likert scale (1-l do not agree at all; 2not agree; 3-undecided; 4-agree; 5-fully agree). Table 2 presents a Research instrument measuring anxiety at delivering presentations.

\section{Statistical analysis}

Data obtained by the questionnaire survey were analysed on the four following steps using various statistical methods: (i) 1st step - Descriptive statistics and reliability analysis calculated for all the variables at the total sample; (ii) 2nd step - Factor analysis that was used to reveal the underlying structure from a large dataset. The variables were included in a dataset under the a priori premise that each variable may be correlated with any factor; (iii) 3rd step - Cluster analysis employed to fulfil the paper goal. Cluster analysis is one of the best ways to comprehend a large set of variables and to separate them into homogenous groups, and (iv) 4th step - Chisquare of cluster membership and demographic characteristics

\section{Descriptive statistics and reliability analysis}

Descriptive statistics and Cronbach's alpha for an observed sample and the research instrument are displayed in Table 3. The average grade is the lowest for Q1_5, research item "Fear of revenge" which indicates that students perceive the fear of revenge as the lowest fear while delivering presentations. On the other hand, the highest average grade has research items from the "Perceived success at delivering a presentation" dimension, the question "I respect the audience and their views when I present" have the highest average grade (4.09) following the "I know well the material I expose when I present" with the average grade 3.91 which means that students are confident about their approach towards their audience as well as their knowledge about presented material.

None of the research questions was excluded from further research as none of the research questions was not above three standard deviations. We included Cronbach's alpha coefficients for four dimensions included in the research, to analyse internal consistency and the reliability of the research instrument. Considering Nunnaly (1994) recommended the cut-off value of 0.70, from which all Cronbach's alpha values are higher, internal consistency and the reliability of the research instrument is confirmed. 
Table 3 Descriptive statistics and Cronbach's alpha

\begin{tabular}{|l|l|l|l|l|l|l|}
\hline & N & Min & Max & Mean & $\begin{array}{l}\text { Std. } \\
\text { Dev. }\end{array}$ & $\begin{array}{l}\text { Cronbach's } \\
\text { alpha }\end{array}$ \\
\hline Fear at delivering presentations \\
\hline Q1_1 & 495 & 1 & 5 & 3.02 & 1.144 & 0.882 \\
Q1_2 & 495 & 1 & 5 & 2.76 & 1.147 & \\
Q1_3 & 495 & 1 & 5 & 2.68 & 1.250 & \\
Q1_4 & 495 & 1 & 5 & 2.26 & 1.209 & \\
Q1_5 & 495 & 1 & 5 & 2.06 & 1.073 & \\
Q1_6 & 495 & 1 & 5 & 2.17 & 1.162 & \\
\hline Problems while delivering the presentation \\
\hline Q2_1 & 495 & 1 & 5 & 2.48 & 1.092 & 0.801 \\
Q2_2 & 495 & 1 & 5 & 2.16 & 1.063 & \\
Q2_4 & 495 & 1 & 5 & 2.37 & 1.059 & \\
Q2_5 & 495 & 1 & 5 & 2.63 & 1.078 & \\
Q2_6 & 495 & 1 & 5 & 2.38 & 1.060 & \\
\hline Perceived success at delivering a presentation & \\
\hline Q3_1 & 481 & 1 & 5 & 3.91 & 0.948 & 0.818 \\
Q3_2 & 487 & 1 & 5 & 3.63 & 0.943 & \\
Q3_3 & 480 & 1 & 5 & 4.09 & 0.985 & \\
Q3_4 & 486 & 1 & 5 & 3.59 & 1.053 & \\
Q3_5 & 488 & 1 & 5 & 3.30 & 0.955 & \\
\hline Strategies in stimulating audience attention when presenting \\
\hline Q4_1 & 495 & 1 & 5 & 2.54 & 1.077 & 0.823 \\
Q4_2 & 495 & 1 & 5 & 2.49 & 1.087 & \\
Q4_3 & 495 & 1 & 5 & 2.86 & 1.001 & \\
Q4_4 & 495 & 1 & 5 & 3.09 & 1.061 & \\
Q4_5 & 495 & 1 & 5 & 2.34 & 1.062 & \\
Q4_6 & 495 & 1 & 5 & 2.81 & 1.089 & \\
Q4_7 & 495 & 1 & 5 & 2.23 & 1.071 & \\
\hline
\end{tabular}

Source: Authors' work.

\section{Factor analysis}

Factor analysis is conducted to extract common factors from the analysis. Factor analysis is a multivariate statistical method that makes the correlation without the same group of data whose purpose is trying to reduce the loss of information (Singh, Malik, Mohan, 2004). For this investigation, the principal component analysis method is used, following the Varimax with Kaiser Normalization rotation method.

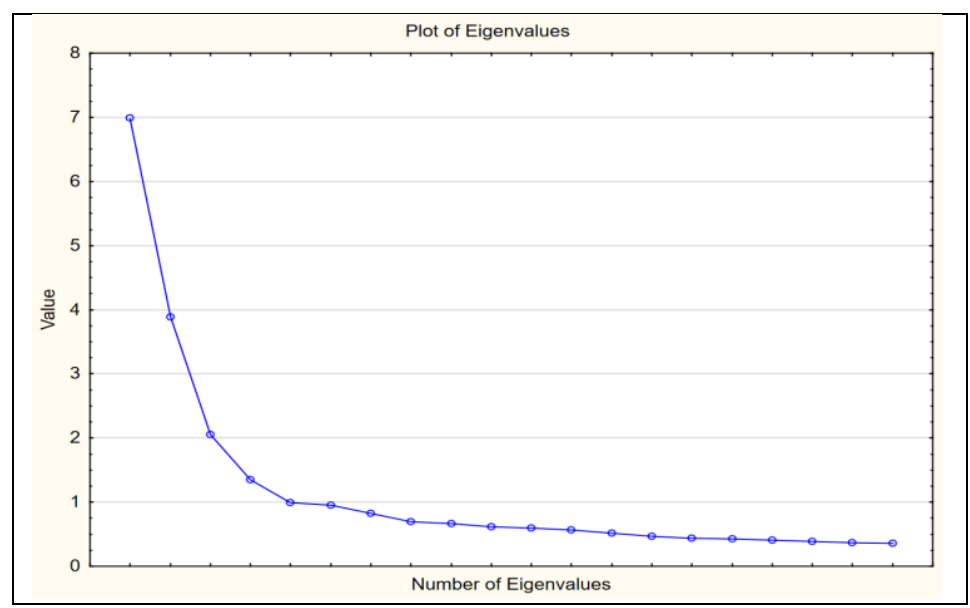

Figure 1 Scree plot

Source: Authors' work. 
The Scree plot available in Figure 1. Shows the relevance of the common factor as well as characteristic root values. The figure shows that the two first two common factors bear the most information in this investigation so they are extracted for further investigation as the main factors.

Table 4 Initial eigenvalues and extraction sums of squared loadings

Source: Authors' work.

\begin{tabular}{|l|l|l|l|l|}
\hline \multirow{4}{*}{ Value } & \multicolumn{3}{|l|}{ Eigenvalues Extraction: Principal components } \\
\cline { 2 - 5 } & Eigenvalue & $\begin{array}{l}\% \text { Total } \\
\text { variance }\end{array}$ & $\begin{array}{l}\text { Cumulative } \\
\text { Eigenvalue }\end{array}$ & $\begin{array}{l}\text { Cumulative } \\
\%\end{array}$ \\
\hline 1 & 6.990524 & 27.96210 & 6.99052 & 27.96210 \\
2 & 3.890122 & 15.56049 & 10.88065 & 43.52258 \\
\hline
\end{tabular}

Table 5 Rotated component matrix

\begin{tabular}{|l|l|l|}
\hline Variable & Factor 1 & \multicolumn{1}{l|}{ Factor 2 } \\
\hline Fear at delivering presentations \\
\hline Q1_1 & 0.705975 & -0.130414 \\
Q1_2 & 0.754119 & -0.089484 \\
Q1_3 & 0.752591 & -0.190796 \\
Q1_4 & 0.759859 & -0.120580 \\
Q1_5 & 0.635054 & -0.011084 \\
Q1_6 & 0.678011 & -0.110280 \\
\hline Problems while delivering the presentation \\
\hline Q2_1 & 0.529116 & -0.114840 \\
Q2_2 & 0.608143 & -0.052374 \\
Q2_3 & 0.761797 & 0.036388 \\
Q2_4 & 0.668512 & 0.076172 \\
Q2_5 & 0.649956 & -0.046567 \\
Q2_6 & 0.745938 & -0.132637 \\
Q2_7 & 0.703136 & -0.013897 \\
\hline Perceived success at delivering a presentation \\
\hline Q3_1 & -0.150922 & 0.564845 \\
Q3_2 & -0.356725 & 0.519020 \\
Q3_3 & -0.099583 & $\mathbf{0 . 4 5 7 7 8 7 * *}$ \\
Q3_4 & -0.066613 & $\mathbf{0 . 6 4 1 1 4 7}$ \\
Q3_5 & -0.187252 & $\mathbf{0 . 6 2 2 1 2 6}$ \\
\hline Strategies in stimulating & audience attention when presenting \\
\hline Q4_1 & -0.063930 & $\mathbf{0 . 7 0 9 5 4 5}$ \\
Q4_2 & -0.018706 & $\mathbf{0 . 6 7 4 7 7 9}$ \\
Q4_3 & -0.102298 & $\mathbf{0 . 7 6 9 7 3 1}$ \\
Q4_4 & -0.033560 & $\mathbf{0 . 7 0 6 4 4 1}$ \\
Q4_5 & 0.072678 & $\mathbf{0 . 6 0 5 1 7 2}$ \\
Q4_6 & -0.011864 & $\mathbf{0 . 3 9 4 8 8 1 * *}$ \\
Q4_7 & 0.071687 & $\mathbf{0 . 4 8 3 2 6 5 * *}$ \\
\hline Expl.Var & 0.450218 & 4.430428 \\
\hline Prp.Totl & 0.258009 & 0.177217 \\
\hline
\end{tabular}

Note: ${ }^{* *}$ excluded from analysis due to the low factor loadings.

Source: Authors' work. 
The initial eigenvalues extraction and extraction sums of squared loadings are presented in Table 4. The results show that the first two eigenvalues of the common factors denoted as 1 and 2 have the variance contribution $27.96 \%$ and $15,16 \%$ and the total cumulative variance contribution rate $43.52 \%$.

Table 5 shows factor loadings normalised with the Kaiser Normalization method. Table 5 shows a rotated component matrix, where factor loadings normalized with the Kaiser Normalization method are presented. The extraction method was the Principal components. Following the results presented in Table 5, the variables (items) Q3_3, Q4_6, and Q4_7 are excluded from the further investigation; since their values are, lower than 0.5 .

\section{Cluster analysis}

The cluster analysis with the K-means algorithm has been conducted to systematize research data into meaningful structures. The maximum average distance was applied to determine initial centroids. Subsequently, the Squared Euclidian distance was applied to iteratively distribute research data to the cluster with the closest centroid.

Figure 2 presents the graph of cost sequence, which displays the error function for the various numbers of clusters and proposed the best numbers of clusters for the given dataset. The error function presented can be explained as the average distance of observations in tested research to the cluster centroids to which the observations were assigned (Tibshirani, Walther, Hastie, 2001).

The goal is to minimise the cluster cost to the desirable level. The graph recommends two clusters as the best number of clusters to be included in this investigation. However, the graph shows a continuous decrease of the error function, without a point where it would stop decreasing. Therefore, the four-cluster solution was selected as an optimal one, and four clusters will be observed in further investigation.

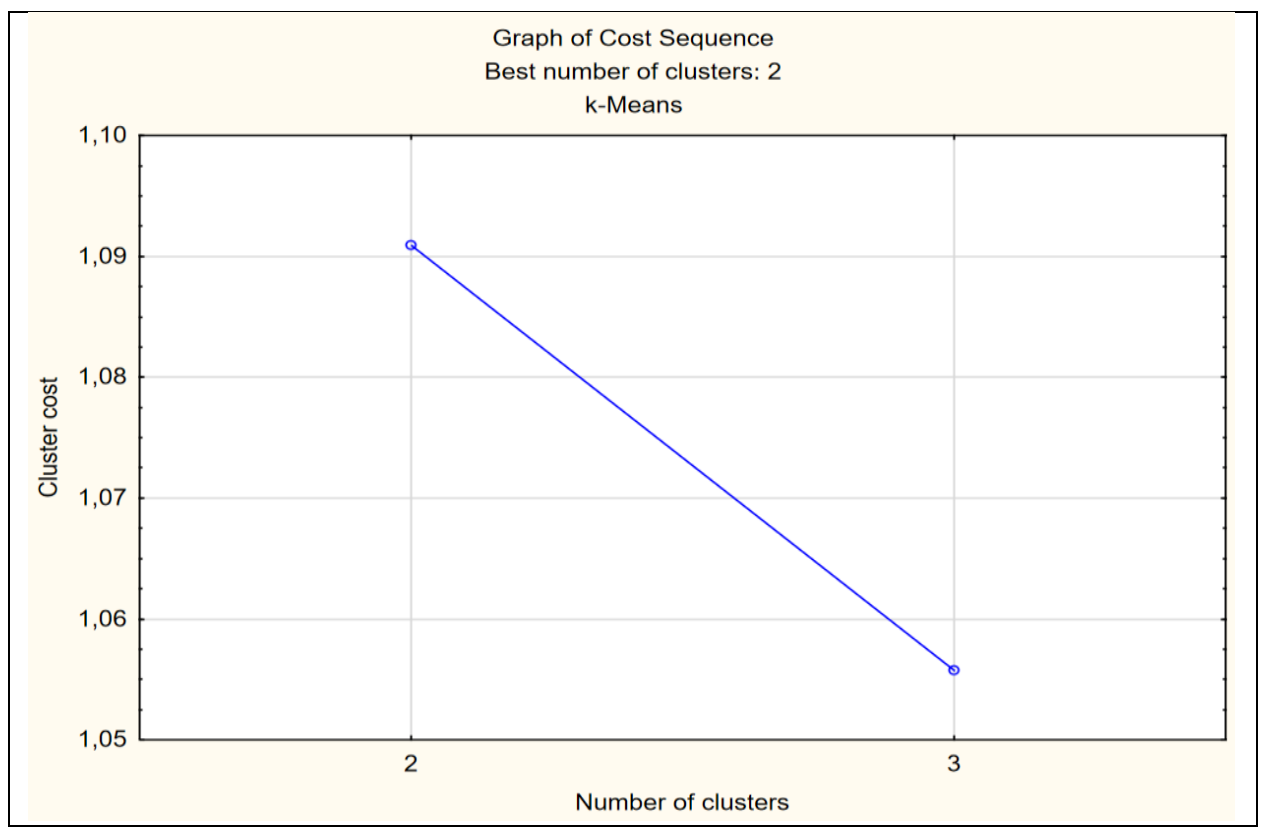

Figure 2 Graph of Cost Sequences

Source: Authors' work (2020)

Furthermore, the ANOVA analysis was conducted for four clusters. Table 2 shows the 22 items left in the research without three items excluded in the previous steps. 
Table 6. ANOVA analysis

\begin{tabular}{|l|l|l|l|l|l|l|}
\hline & Between SS & df & Within SS & N & F & P-value \\
\hline Q1_1 & 244.898 & 3 & 357.882 & 468 & 106.751 & $0.000^{* * *}$ \\
Q1_2 & 285.511 & 3 & 318.724 & 468 & 139.744 & $0.000^{* * *}$ \\
Q1_3 & 387.663 & 3 & 336.013 & 468 & 179.979 & $0.000^{* * *}$ \\
Q1_4 & 325.468 & 3 & 354.275 & 468 & 143.315 & $0.000^{* * *}$ \\
Q1_5 & 167.989 & 3 & 366.416 & 468 & 71.521 & $0.000^{* * *}$ \\
Q1_6 & 265.690 & 3 & 357.274 & 468 & 116.011 & $0.000^{* * *}$ \\
Q2_1 & 120.389 & 3 & 427.475 & 468 & 43.934 & $0.000^{* * *}$ \\
Q2_2 & 149.556 & 3 & 376.775 & 468 & 61.922 & $0.000^{* * *}$ \\
Q233 & 245.498 & 3 & 309.416 & 468 & 123.774 & $0.000^{* * *}$ \\
Q2_4 & 155.861 & 3 & 375.730 & 468 & 64.712 & $0.000^{* * *}$ \\
Q2_5 & 170.423 & 3 & 369.659 & 468 & 71.920 & $0.000^{* * *}$ \\
Q2_6 & 422.752 & 3 & 390.765 & 468 & 168.770 & $0.000^{* * *}$ \\
Q2_7 & 190.206 & 3 & 334.498 & 468 & 88.706 & $0.000^{* * *}$ \\
Q3_1 & 47.771 & 3 & 372.492 & 468 & 20.007 & $0.000^{* * *}$ \\
Q3_2 & 85.300 & 3 & 322.749 & 468 & 41.230 & $0.000^{* * *}$ \\
Q3_4 & 80.641 & 3 & 441.969 & 468 & 28.464 & $0.000^{* * *}$ \\
Q3_5 & 72.531 & 3 & 346.111 & 468 & 32.691 & $0.000^{* * *}$ \\
Q4_1 & 130.462 & 3 & 389.519 & 468 & 52.249 & $0.000^{* * *}$ \\
Q4_2 & 132.564 & 3 & 416.959 & 468 & 49.597 & $0.000^{* * *}$ \\
Q4_3 & 144.928 & 3 & 319.511 & 468 & 70.761 & $0.000^{* * *}$ \\
Q4_4 & 128.839 & 3 & 396.712 & 468 & 50.664 & $0.000^{* * *}$ \\
Q4_5 & 88.556 & 3 & 417.899 & 468 & 33.058 & $0.000^{* * *}$ \\
\hline
\end{tabular}

Source: Authors' work.

The table suggested that the null hypothesis, which indicates that the means between the indicator observed statistically differ has been rejected at the $1 \%$ statistical significance so all variables are statistically significant. The given results confirm that the selection of four clusters to analyse data is justified.

\section{Relationship of cluster membership and demographic characteristics}

Chi-square cluster membership and demographic characteristics have been comprised to identify the relationship between clusters that emerged from the investigation and specific demographic characteristics.

The results presented in the first cluster membership table shows the relationship between the four structured clusters and gender. From a total of 472 students answers who participated in the cluster analysis, 354 female and 118 male students participated.

Cluster 1 consists of the most participants, 148, from which 109 are females, and 39 are males. In Cluster 2, from a total of 131 students included, 101 are females, and 30 are males. Cluster 3 contained the fewest students, a total of 82 , from which are 61 females, and 21 male students. Cluster 4 contained a total of 111 students, 83 females, and 28 males. The results present similar gender distributions in clusters, male distribution from $22-26 \%$, and females from $73-78 \%$.

The male students are the most represented in Cluster 1 and the least in Cluster 2 , and female vice-versa. However, Pearson Chi-square and M-L chi-square did not 
confirm the statistically significant relationship between gender and cluster membership as shown in Table7 and Table 8.

Table 7 Cross-tabulation of gender and cluster membership

\begin{tabular}{|l|l|l|l|l|l|}
\hline \multirow{3}{*}{ Gender } & \multicolumn{4}{|l|}{ 2-Way Summary Table: Gender x Cluster } \\
\cline { 2 - 6 } & Cluster 1 & Cluster 2 & Cluster 3 & Cluster 4 & Total \\
\hline Male & 39 & 30 & 21 & 28 & 118 \\
\hline Female & 109 & 101 & 61 & 83 & 354 \\
\hline Total & 148 & 131 & 82 & 111 & 472 \\
\hline
\end{tabular}

Source: Authors' work.

Table 8 Chi-square for cluster membership and gender

Source: Authors' work.

\begin{tabular}{|l|l|l|l|}
\hline \multirow{2}{*}{ Statistic } & \multicolumn{3}{|l|}{ Statistics: Gender $\times$ Cluster } \\
\cline { 2 - 4 } & Chi-square & $\mathrm{df}$ & $\mathrm{p}$ \\
\hline Pearson Chi-square & 0.4712954 & $\mathrm{df}=3$ & $\mathrm{p}=0.92515$ \\
\hline M-L Chi-square & 0.4755649 & $\mathrm{df}=3$ & $\mathrm{p}=0.92423$ \\
\hline
\end{tabular}

The second results from the analysis demonstrate the weak association between age groups and Clusters. A total of 77 students age 19 were, 32 students age 20, 197 students age 21, 89 students age 22 , and 77 students age 23 , and more were included in the final investigation.

The age group 19 is distributed the most in Cluster 1 and the least in Cluster 2. Students of age 20 are grouped evenly with a deviation of 1 student. Students of age 21 are concentrated the highest in Cluster 1, following Cluster 2, and have by far the lowest concentration in Cluster 3. Age groups 22 and 23 and more have a similar distribution between Clusters 1, 2, and 4 with a much lower number of students in Cluster 3, which means that the older students are underrepresented in Cluster 3. In conclusion, it can be highlighted that younger students are less represented in Cluster 2 , and more in Cluster 3, as well as the other Clusters, there is no significant difference between clusters. However, Pearson Chi-square and M-L chi-square did not confirm the statistically significant relationship between any of the age groups and clusters. Tables 9 and 10 show observed frequencies and Chi-square of cluster membership and age.

Table 9 Cross-tabulation between age and cluster membership

Source: Authors' work.

\begin{tabular}{|l|l|l|l|l|l|}
\hline \multirow{2}{*}{ Age } & \multicolumn{5}{|l|}{ 2-Way Summary Table: Age x Cluster } \\
\cline { 2 - 6 } & Cluster 1 & Cluster 2 & Cluster 3 & Cluster 4 & Totals \\
\hline 19 & 26 & 15 & 16 & 20 & 77 \\
\hline 20 & 7 & 8 & 8 & 9 & 32 \\
\hline 21 & 71 & 62 & 29 & 35 & 197 \\
\hline 22 & 22 & 25 & 17 & 25 & 89 \\
\hline 23 and more & 22 & 21 & 12 & 22 & 77 \\
\hline Totals & 148 & 131 & 82 & 111 & 472 \\
\hline
\end{tabular}


Table 10 Chi-square for cluster membership and age

Source: Authors' work.

\begin{tabular}{|l|l|l|l|}
\hline \multirow{2}{*}{ Statistic } & \multicolumn{3}{|l|}{ Statistics: Age $\times$ Cluster } \\
\cline { 2 - 4 } & Chi-square & $\mathrm{df}$ & $\mathrm{p}$ \\
\hline Pearson Chi-square & 19.23040 & $\mathrm{df}=18$ & $\mathrm{p}=0.37777$ \\
\hline M-L Chi-square & 20.56301 & $\mathrm{df}=18$ & $\mathrm{p}=0.30203$ \\
\hline
\end{tabular}

Table 11 Cross-tabulation between the type of school and cluster membership

\begin{tabular}{|l|l|l|l|l|l|}
\hline \multirow{2}{*}{ School } & \multicolumn{4}{|l|}{ 2-Way Summary Table: School x Cluster } \\
\cline { 2 - 7 } & Cluster 1 & Cluster 2 & Cluster 3 & Cluster 4 & Total \\
\hline Gymnasium & 87 & 70 & 43 & 48 & 248 \\
\hline Business secondary school & 52 & 52 & 36 & 55 & 195 \\
\hline Another secondary school & 9 & 9 & 3 & 8 & 29 \\
\hline Totals & 148 & 131 & 82 & 111 & 472 \\
\hline
\end{tabular}

Source: Authors' work.

Table 12 Chi-square for cluster membership and type of school

\begin{tabular}{|l|l|l|l|}
\hline \multirow{2}{*}{ Statistic } & \multicolumn{4}{|l|}{ Statistics: School Cluster } \\
\cline { 2 - 4 } & Chi-square & $\mathrm{df}$ & $\mathrm{p}$ \\
\hline Pearson Chi-square & 7.492339 & $\mathrm{df}=6$ & $\mathrm{p}=0.27770$ \\
\hline M-L Chi-square & 7.657710 & $\mathrm{df}=6$ & $\mathrm{p}=0.26427$ \\
\hline
\end{tabular}

Source: Authors' work.

The third results show a weak relationship between cluster membership and the type of school. Students from the gymnasium are mostly concentrated in Cluster 1 and all of the students from business and the other schools show even distributions among Clusters 1, 2 and 4 with the lower rate of distribution among Cluster 3. However, Pearson Chi-square and $M-L$ chi-square did not confirm the statistical difference between genders as the $\mathrm{p}$ values are higher than alpha so the 0th hypotheses cannot be rejected. Tables 11 and 12 present observed frequencies and Chi-square of cluster membership and age.

\section{Discussion}

The k-means cluster analysis of survey responses was undertaken from the 472 Business and Economy students from Croatia, which were included in final investigations. Figure 3 presents the graph of mean values of 22 item survey responses left in the research across four identified clusters. Given cluster, means reveal the existence of differences between clusters according to the observed individual indicators the survey responses (Figure 3).

By comparing cluster means, some interesting conclusions about student groups can be brought. A similar pattern trend has been observed for all clusters included, however, the responses are displayed on different levels. Furthermore, taking into account all observed items, research items from the question group "Perceived success at delivering a presentation" obtained the highest mean values, which also correlate with descriptive statistic results. Additionally, trends for all other question groups are similar. Cluster 2 and Cluster 3 show the most similar cluster means pattern for Q1 and Q2 question groups, as for the Q3 and Q4 Clusters 1, 3, and 4 display similar answer patterns, which are indicated by similar variables numbers. 


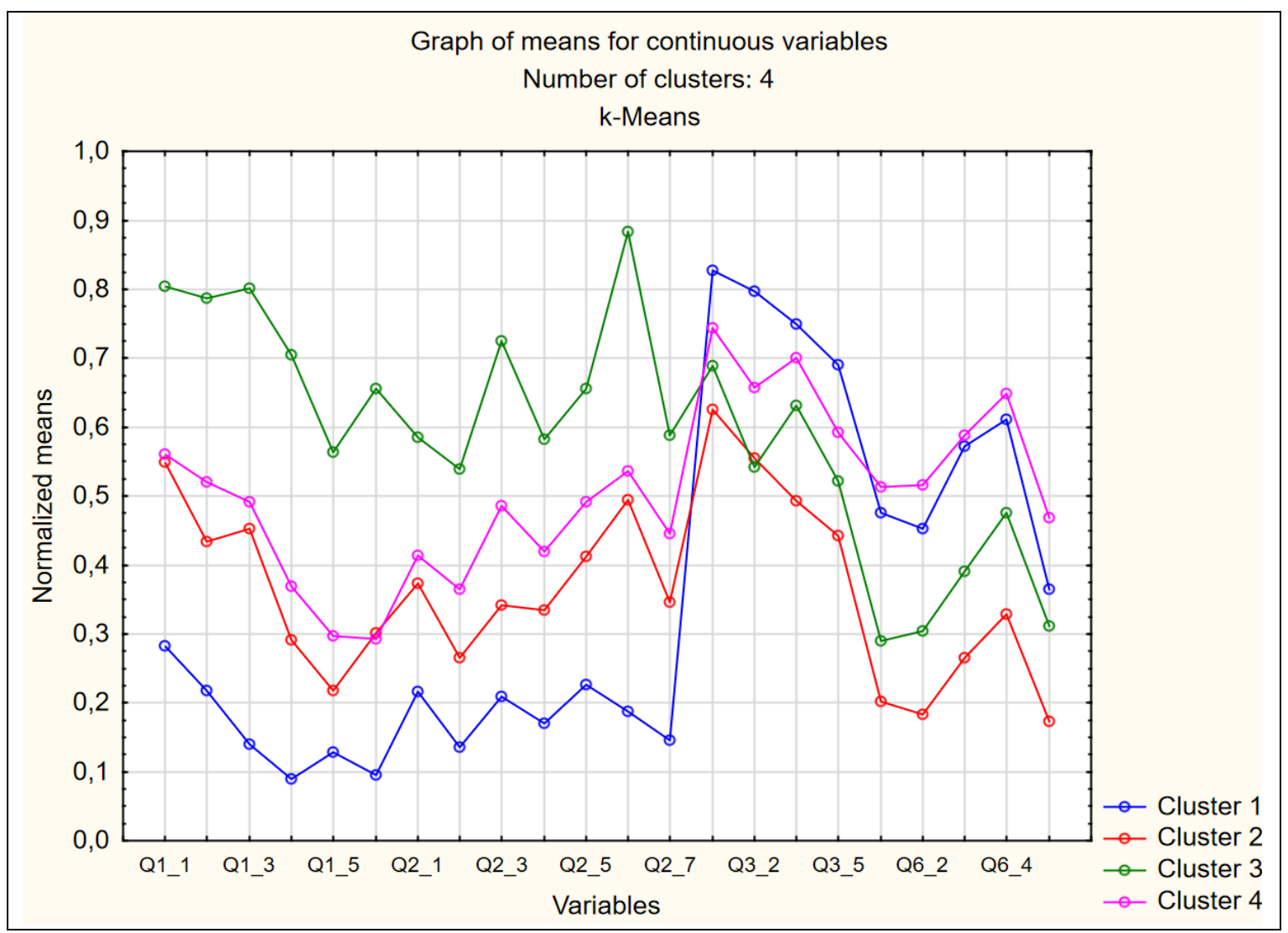

Figure 3 Standardized cluster means

Source: Authors' work.

Based on the mutual relationship of various answers of the four investigated dimensions, clusters can be described in the following manner:

Cluster 1 students group has the lowest average values for variables from "Fear at delivering presentations" groups of questions. Questions "Fear that my colleagues will make fun of me" and "Fear of revenge" are have the lowest mean values, which indicate that students from Cluster 1 perceive the lowest fears of their colleagues. The average means for the variable "I know well the material I expose when I present" are the highest among the Cluster 1 results. All mean values for the group of questions: "Perceived success at delivering a presentation" are the highest within all results, which could connect the students from Cluster 1 with high confidence. This group could be called: Self-confident.

For the students grouped in Cluster 2, the highest average values have been calculated for their presentation material knowledge, but with significantly lower normalized means than Cluster 1. Students in Cluster 2 express mid-level fear. Furthermore, Cluster 2 students comprise the lowest values for both "Strategies in stimulating audience attention when presenting" and "Problems while delivering presentation" groups of questions of all students included in the research. The results for Cluster 2 demonstrate that the students included in the Classroom shows a low level of interest in delivering presentations, which influences their perceived presentation performance. This group could be called: Not-interested.

Cluster 3 student group resulted in a group with the highest values for the "fear of the presentation delivery" dimension, and the lowest for the confidence related dimensions. The question "What if my voice starts to tremble?" which represent the fear that the audience will detect insecurities while presenting, obtained the highest normalized means in all questionnaire. Alongside this fear, students from Cluster 3 
expressed high-perceived fear from the unsuccessful presentation, being criticised, and being mocked. Furthermore, the Cluster results in outcome with the lowest values overall for the "Strategies in stimulating audience attention when presenting" group of questions, such as interaction with the public, making pauses, and surprising the audience, which all correlate with a high level of insecurity among Cluster 3 student group. This group could be labelled as Anxious.

Cluster 4 students have the highest variable means for the question group "Perceived success at delivering presentation" same as the students from Cluster 1. However, the students from Cluster 4 had lower means to the item "I look convincing when I present" which indicates that the students from Cluster 4 show a bit more insecurity than a student from Cluster 1. Nevertheless, the Cluster 4 students have the highest results for the question group "Strategies in stimulating audience attention when presenting" from all the four clusters, which could be connected with their attention to details and strategical thinking. Students from Cluster 4 have the lowest means for variables related to colleagues making fun of them, which shows maturity and confidence. This group could be called Strategic.

\section{Conclusion}

The purpose of this research was to explore the business students' attitudes toward presentation delivery, and investigate if there are homogenous groups of students according to their attitude towards the presentation, both as sources of success and as a source of fear.

To fulfil the paper goals, a cross-analysis has been undertaken. Descriptive statistics and reliability analysis were calculated for all the variables in the total sample. Factor analysis was performed to unveil the underlying structures of the data, and the cluster analysis to explore can students be grouped according to their attitude towards presentation. Finally, the Chi-square of cluster membership and demographic characteristics has been conducted to explore the possible relationship between demographic characteristics and cluster membership.

Interesting findings emerged from the investigation. Firstly, the result confirms that there are homogenous groups of students according to presentation perceived benefits and fears. The investigation identified four different student groups based on their confidence and interests: Self-confident, Non-interested, Anxious, and Strategic. However, an investigation concluded there is no relationship between cluster membership and demographic characteristics. The results showed that all students fear the most that their voice will start to tremble and show their insecurities and that all students fear the least the revenge of their colleagues.

The findings from the investigation could be beneficial for both academics and practitioners. Academics could benefit from these investigation results and conduct further analysis to explore student characteristics, which groups them into specific clusters. On the other hand, practitioners could use these results to adapt presentation skill teaching into different clusters to achieve better results and provide each student methods they need the most.

However, his research is not without its limits, for instance, more students could be included in the investigation, and more information about students, such as their grades, hobbies, interests in specific classes so the answer to why some student have the characteristic of specific clusters can be revealed. Considering the emerging numbers of papers on this important topic, this also could be direction for future investigations. 


\section{References}

1. Alshare, K., Hindi, N. M. (2004). The importance of presentation skills in the classroom: Students and instructors perspectives. Journal of Computing Sciences in Colleges, Vol. 19, No. 4, pp. 6-15.

2. Boetje, J., Van Ginkel, S. (2020). The added benefit of an extra practice session in virtual reality on the development of presentation skills: A randomized control trial. Journal of Computer Assisted Learning, pp. 1-12.

3. Brynjolfsson, E., Rock, D., Syverson, C. (2017). Artificial intelligence and the modern productivity paradox: A clash of expectations and statistics. National Bureau of Economic Research.

4. C,etin, P. S., Eymur, G. (2017). Developing students' scientific writing and presentation skills through argument driven inquiry: an exploratory study. Journal of Chemical Education, Vol. 94, No. 7, pp. 837-843.

5. Christianson, M., Payne, S. (2011). Helping students develop skills for better presentations: Using the 20x20 format for presentation training. Language Research Bulletin, No. 26, pp. 115.

6. Ciarocco, N. J. (2018). Traditional and new approaches to career preparation through coursework. Teaching of Psychology, Vol. 45, No. 1, pp. 32-40.

7. Coffelt, T. A., Baker, M. J., Corey, R. C. (2016). Business communication practices from employers' perspectives. Business and Professional Communication Quarterly, Vol. 79, No. 3, pp. 300-316.

8. Dede, C. (1996). The evolution of distance education: Emerging technologies and distributed learning. American Journal of Distance Education, Vol. 10, No. 2, pp. 4-36.

9. Dell'Osso I., Saettoni, M., Papasogli, A., Rucci, P., Ciapparelli, A., Di Poggio, A. B., Cassano, G. B. (2002). Social anxiety spectrum: gender differences in Italian high school students. The journal of nervous and mental disease, Vol. 190, No. 4, pp. 225-232.

10. Henard, F., Roseveare, D. (2012). Fostering quality teaching in higher education: Policies and practices. An IMHE Guide for Higher Education Institutions, pp. 7-11.

11. Cleverism (2020). Presentation skills. Available at https://www.cleverism.com/skills-andtools/presentation-skills/ [20 October 2020].

12. Leigh, E., Clark, D. M. (2018). Understanding social anxiety disorder in adolescents and improving treatment outcomes: applying the cognitive model of Clark and Wells (1995). Clinical child and family psychology review, Vol. 21, No. 3, pp. 388-414.

13.Lent, R. W. (2018). Future of work in the digital world: Preparing for instability and opportunity. The Career Development Quarterly, Vol. 66, No. 3, pp. 205-219.

14.McGovern, E., Moreira, G., Luna-Nevarez, C. (2020). An application of virtual reality in education: Can this technology enhance the quality of students' learning experience? Journal of Education for Business, Vol. 95, No. 7, pp. 490-496.

15. Mohammed, M. M. A. (2019). Investigating the Effect of Using Vocabulary Learning Strategies on Oral Communication. Doctoral dissertation, Sudan University of Science and Technology.

16.Nunnally, J. C. (1994). Psychometric theory. Tata McGraw-Hill education.

17.Popescu, T. (2013). Improving business students' presentation skills. The Journal of Linguistic and Intercultural Education, Vol. 6, pp. 127-136.

18.Ramesh, G. (2010). The ace of soft skills: attitude, communication and etiquette for success. Pearson Education India.

19.Roussel, S., Joulia, D., Tricot, A., Sweller, J. (2017). Learning subject content through a foreign language should not ignore human cognitive architecture: A cognitive load theory approach. Learning and Instruction, Vol. 52, pp. 69-79.

20.Roy, A., Macchiette, B. (2005). Debating the issues: A tool for augmenting critical thinking skills of marketing students. Journal of Marketing Education, Vol. 27, No. 3, pp. 264-276.

21.Rubin, R. B., Rubin, A. M., Jordan, F. F. (1997). Effects of instruction on communication apprehension and communication competence. Communication Education, Vol. 46, No. 2, pp. 104-114. 
22.Salem, A. A. (2019). A Sage on a Stage, to Express and Impress: TED Talks for Improving Oral Presentation Skills, Vocabulary Retention and Its Impact on Reducing Speaking Anxiety in ESP Settings. English Language Teaching, Vol. 12, No. 6, pp. 146-160.

23.Sideridis, G. D., Kafetsios, K. (2008). Perceived parental bonding, fear of failure and stress during class presentations. International Journal of Behavioral Development, Vol. 32, No. 2 , pp. 119-130.

24.Šimičević, V., Jurić, V., Ćurlin, T. (2020). Fear at Delivering Presentations: Relations to Age. In Proceedings of the ENTRENOVA-ENTerprise REsearch InNOVAtion Conference, pp. 37-49.

25.Singh, K. P., Malik, A., Mohan, D., Sinha, S. (2004). Multivariate statistical techniques for the evaluation of spatial and temporal variations in water quality of Gomti River (India)- a case study. Water research, Vol. 38, No. 18, pp. 3980-3992.

26.Sugeng, B., Suryani, A. W. (2018). Presentation-Based Learning and Peer Evaluation to Enhance Active Learning and Self-Confidence in Financial Management Classroom. Malaysian Journal of Learning and Instruction, Vol. 15, No. 1, pp. 173-201.

27.Sukitkanaporn, T., Phoocharoensil, S. (2014). English Presentation Skills of Thai Graduate Students. English Language Teaching, Vol. 7, No. 3, pp. 91-102.

28.Susskind, J. E. (2005). PowerPoint's power in the classroom: Enhancing students' self-efficacy and attitudes. Computers \& education, Vol. 45, No. 2, pp. 203-215.

29.Tibshirani, R., Walther, G., Hastie, T. (2001). Estimating the number of clusters in a data set via the gap statistic. Journal of the Royal Statistical Society: Series B (Statistical Methodology), Vol. 63, No. 2, pp. 411-423.

30. Van Ginkel, S., Gulikers, J., Biemans, H., Mulder, M. (2017). The impact of the feedback source on developing oral presentation competence. Studies in Higher Education, Vol. 42, No. 9, pp. 1671-1685.

31.Werthes, D., Maver, R., Brettel, M. (2018). Cultural and creative entrepreneurs: understanding the role of entrepreneurial identity. International Journal of Entrepreneurial Behavior \& Research, Vol. 24, No. 1, pp. 290-314.

\section{About the authors}

Tamara Ćurlin is a Teaching Assistant and a PhD student at the Faculty of Economics and Business, University of Zagreb, Department of Informatics. She received her BSc and MSC degrees from the Faculty of Economics and Business, University of Zagreb. She is teaching Informatics and Enterprise Information Systems courses exercises. Her current research interests include Information Technologies in Tourism and Hospitality, Mobile Technologies, Knowledge management and Information management. The author can be contacted at tcurlin@efzg.hr.

Mirjana Pejić Bach, PhD is a Full Professor of System Dynamics Modelling, Managerial Simulation Games and Data Mining at the Faculty of Economics and Business, University of Zagreb, Department of Informatics. Her current research areas are system dynamics modelling, data mining and web content research. She is actively engaged in several scientific projects (FP7ICT, bilateral cooperation, national projects). The author can be contacted at mpejic@efzg.hr.

Ivan Miloloža, PhD graduated from the Faculty of Economics and Business in Zagreb and received a PhD at the Faculty of Economics in Osijek in 2015. He lived and worked abroad in the period from 1983 to 1986 (Argentina and the Netherlands). Since 1986, he has been employed by Munja, the only Croatian battery manufacturer, where he has performed virtually all management functions and is currently the CEO of the Board (since 1999). He is Assistant Professor at the Department of Dental Medicine and Health, Dean for Institutional Cooperation and Development and Chair of the Department of History of Medicine and Social Sciences. He has performed many social functions in various state bodies, associations, and banks, and was a participant and guest lecturer at numerous domestic and foreign faculties and international conferences. The author can be contacted at ivan.miloloza@fdmz.hr. 